\title{
A Comparative Study of the Effects of Substrate Composite Materials on External and Internal Handset Antenna EM Absorption
}

\author{
Md Ikbal HOSSAIN ${ }^{1}$ *, Mohammad Rashed Iqbal FARUQUE ${ }^{2}$, \\ Mohammad Tariqul ISLAM ${ }^{1,2}$
}

\author{
${ }^{1}$ Center for Space Science, Universiti Kebangsaan Malaysia, 43600 UKM, Bangi, Selangor D.E., Malaysia \\ ${ }^{2}$ Department of Electrical, Electronic and Systems Engineering, Universiti Kebangsaan Malaysia, 43600 UKM, Bangi, \\ Selangor D.E., Malaysia
}

cross $^{\text {ref }}$ http://dx.doi.org/10.5755/j01.ms.22.3.8889

Received 11 December 2014; accepted 17 May 2015

\begin{abstract}
Cellular phones are used in the vicinity of a human head, which absorbs power from antenna radiation. This investigation analyzes the effects of antenna substrate materials on electromagnetic (EM) absorption in a human head. Antennas are used in analysis with four different dielectric substrate materials, which are Bakelite, FR4 glass epoxy, Rogers R04003, and Taconic TLC. Moreover, two different thicknesses of each substrate are considered in the experimental setup. The EM absorption associated with two types of cell phone antennas is evaluated in the closed vicinity of the human head model. One of them is planar inverted-F antenna (PIFA), which is used as the internal handset antenna and another one is helical antenna, which is used as external handset antenna. This investigation consists of two different operating frequency bands, GSM $900 \mathrm{MHz}$ and DCS $1800 \mathrm{MHz}$. The EM absorption in the human head is presented using the peak specific absorption rate (SAR) and total absorbed power (TAP) by the user. The finite-difference time-domain (FDTD) method based on Computer Simulation Technology (CST) Microwave studio is utilized in this investigation. The obtained results show that the substrate materials do not effect SAR and TAP values considerably for both antennas, but substrate thickness affects the SAR and TAP values significantly. In addition, the substrate thickness affects the SAR and TAP values significantly in most of the cases Moreover, PIFA produces lower SAR than that of a helical antenna significantly for both GSM and DCS frequency band.

Keywords: EM absorption, helical antenna, PIFA, SAR, substrate materials.
\end{abstract}

\section{INTRODUCTION}

The EM radiation from mobile terminal antenna can disturb the human biological system and may harm human health. The World Health Organization (WHO) has declared that the use of cell phone potentially cause brain cancer $[1,2]$. It is also found that the cell phone radiation doubles the risk of a brain tumor at side of head, which is closed to the cell phone for more than 10 years use [3]. Besides, thermal effect can occur when human tissues exposed to infinite EM energy [4]. Due to the enormous uses of portable handset, a lot of concerns regarding cell phone safety have been discussed. The interaction between RF radiation and human tissues are expressed in terms of SAR, which denotes absorbed power by the human body over a certain volume of biological tissues [5]. Several standard organizations are responsible for imposing SAR limit for the safety of the human body, including ICNIRP in Europe [6] and FCC in United State [7]. The maximum SAR limit for portable devices is set $2 \mathrm{~W} / \mathrm{Kg}$ averaged over the mass of $10 \mathrm{~g}$ of body tissue by ICNRIP and $1.6 \mathrm{~W} / \mathrm{Kg}$ over $1 \mathrm{~g}$ of tissue by the FCC.

Several factors may affect SAR values such as EM source geometry and frequency, the user body tissue size and their properties. The SAR values depend on the medium and distance between source and user body. The SAR values may be varied due to variation of antenna

* Corresponding author. Tel.: +60188729604

E-mail address: ipk_eee@yahoo.com (M.I. Hossain) geometry also. An analysis of SAR values using different types of antenna (i.e. mono-pole, helical, patch and Planar Inverted-F Antenna) showed that the mono-pole antenna generates the utmost SAR levels in all tissues, where the patch antenna produces low level of SAR values [8]. However, the first generation of mobile phone antenna was external antenna, which usually mounted on the top of cell phone body. But, the recent trend is to use internal and planar antenna for handset devices as it allows multiple frequency band operation and fulfills compact size requirements of modern handset. It was investigated in [9] that the handsets with built-in antennas (internal antenna) show significant variation in the SAR values than that of handsets with external antennas. It was also claimed from previous research that PIFA structures produced low SAR in the head tissue [10]. Moreover, the antenna substrate material has also some effects on antenna performances and EM absorption in the human head. In [11], an analysis of microstrip-fed patch antenna design using four different substrate material was presented. The results revealed that the antenna substrate materials affect the antenna reflection coefficient significantly. In [2], an analysis of SAR in the human head was presented comprising three types of substrate material for the helical antenna. The authors concluded that the conductivity of the helical antenna substrate significantly influenced SAR values.

The purpose of this investigation is to compare the effects of substrate materials on EM absorption between external and internal handset antennas. A PIFA and a 
helical antenna are used as internal and external antenna of mobile phone respectively. Both antennas have dual band characteristics operating at GSM $900 \mathrm{MHz}$ and DCS $1800 \mathrm{MHz}$. The peak SAR values in the human head and total absorbed power are evaluated for both antennas with varying antenna substrate materials.

\section{MODELS AND METHODS}

\subsection{Antennas}

The geometry of the dual band helical antenna mounted on a conducting box is presented in Fig. 1 a. The design of helix is collected from [12]. The length and diameter of the helix are $18 \mathrm{~mm}$ and $5 \mathrm{~mm}$ respectively. For the dual band behavior of helical antenna is achieved using non-linear pitch along helix length. The helix is made of perfect electric conductor (PEC). The dimensions of conducting box are $100 \mathrm{~mm} \times 40 \mathrm{~mm} \times 20 \mathrm{~mm}$. Fig. $1 \mathrm{~b}$ demonstrates detailed geometry of E-shaped PIFA, which is designed for dual band operation. The dimension of the substrate is $100 \mathrm{~mm} \times 40 \mathrm{~mm} \times 0.8 \mathrm{~mm}$. The distance between the ground plane and patch is $8 \mathrm{~mm}$. The dimension of shorting plane and feed are $8 \mathrm{~mm} \times 1 \mathrm{~mm} \times 0.2 \mathrm{~mm}$ and $4 \mathrm{~mm} \times 1 \mathrm{~mm} \times 0.2 \mathrm{~mm}$ respectively. The E-shaped patch dimension is $40 \mathrm{~mm} \times 20 \mathrm{~mm} \times 0.2 \mathrm{~mm}$. The PEC material is also used for PIFA patch, feed and shorting wall. For both PIFA and helical antenna, five different dielectric substrate materials-Bakelite, FR4 glass epoxy, Rogers RO4003, and Taconic TLC are used to take effects of substrate materials. The properties of substrate materials are included in Table 1. However, a complete phone model consists of casing, battery, circuits, keyboard, and LCD display has been used in this investigation. But, the effects of other handset components are not focused in this comparative study of substrate materials.

Table 1. The electrical properties of substrate materials

\begin{tabular}{|l|c|c|c|c|}
\hline Materials & $\begin{array}{c}\text { Permittivity, } \\
\varepsilon \mathrm{r}\end{array}$ & $\begin{array}{c}\text { Tangent } \\
\text { loss }\end{array}$ & $\begin{array}{c}\text { Surface } \\
\text { resistivity, } \\
\mathrm{M} \Omega\end{array}$ & $\begin{array}{c}\text { Density, } \\
\mathrm{kg} / \mathrm{m}^{3}\end{array}$ \\
\hline Bakelite & 4.8 & 0.03 & $5 \times 10^{10}$ & 1400 \\
\hline FR-4 & 4.3 & 0.025 & $2 \times 10^{5}$ & 1850 \\
\hline $\begin{array}{l}\text { Rogers } \\
\text { RO4003 }\end{array}$ & 3.55 & 0.0027 & $4.3 \times 10^{9}$ & 1790 \\
\hline $\begin{array}{l}\text { Taconic } \\
\text { TLC }\end{array}$ & 3 & 0.003 & $1.2 \times 10^{7}$ & 2200 \\
\hline
\end{tabular}

\subsection{Head Model}

The dielectric properties of human tissues, such as permittivity, permeability and conductivity have significant roles in the interaction between EM fields and the human body. The dielectric constants are changed due to change in frequency. On the other hand, the permeability of biological tissues, which depends on the water content of tissues, does not vary with frequency. In this paper, a numerical Anthropomorphic Mannequin (SAM) head model [13], which consists of simulating liquids (for shell and brain), is used according to the IEEE standards. The definitions of dielectric materials for human tissues were collected from [14]. Table 2 indicates the properties of head phantom at $900 \mathrm{MHz}$ and $1800 \mathrm{MHz}$.
Regulatory bodies such as IEEE, and IEC have established product compliance standards to assess exposure levels due to mobile phone and have specified the use of SAM phantom in such assessments.
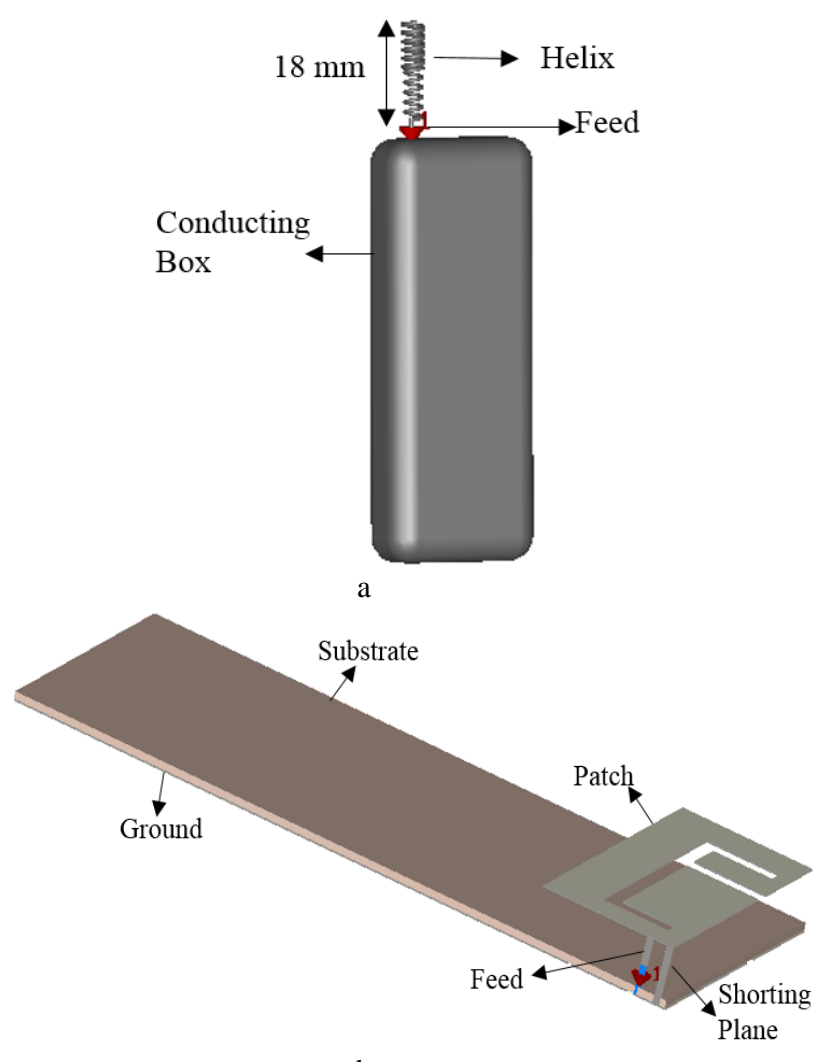

b

Fig. 1. $a-$ dual band helical antenna structure; $b-$ dual band Eshaped PIFA structure

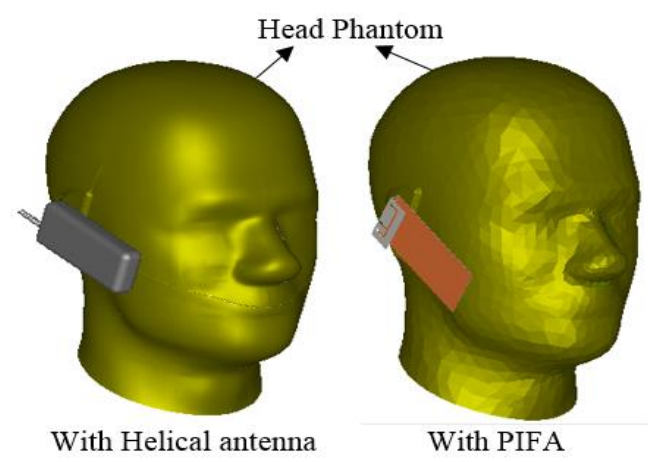

Fig. 2. PIFA and helical antenna with head phantom in talk mode

Fig. 2 indicates the simulation set-up of mobile phone with human head phantom in cheek position [15] of talk mode.

Table 2. The material properties of head phantom

\begin{tabular}{|l|c|c|c|c|}
\hline \multirow{2}{*}{$\begin{array}{l}\text { SAM } \\
\text { material }\end{array}$} & \multicolumn{2}{|c|}{$900 \mathrm{MHz}$} & \multicolumn{2}{c|}{$1800 \mathrm{MHz}$} \\
\cline { 2 - 5 } & $\varepsilon_{\mathrm{r}}$ & $\sigma, \mathrm{S} / \mathrm{m}$ & $\varepsilon_{\mathrm{r}}$ & $\sigma, \mathrm{S} / \mathrm{m}$ \\
\hline SAM shell & 3.7 & 0 & 3.5 & 0.0016 \\
\hline SAM liquid & 41.5 & 0.97 & 40 & 1.42 \\
\hline
\end{tabular}

\subsection{Methods}

The effects on the SAR are studied through an appraisement of the EM energy in a specified tissues domain with the help of a three dimensional finitedifference time-domain (FDTD) technique [16] which is 
performed by the commercial software from Computer Simulation Technology (CST) Microwaves (MWS) studio [17].

The source and radiation impedance of the antenna $\left(Z_{R}=R_{R}+j X_{R}\right)$ determine the power radiated from an antenna which can be evaluated by utilizing Eq. 1 [18]:

$P_{R}=\frac{1}{2} V_{S}^{2} \frac{R_{R}}{\left(Z_{R}+Z_{S}\right)^{2}}$,

where, $V_{\mathrm{S}}$ and $Z_{\mathrm{S}}$ represent source voltage and impedance respectively.

The total absorbed power by the user's head can be calculated by Eq. 2 [16]:

$P_{a b s}=\frac{1}{2} \int_{V} \sigma|E|^{2} d v$.

SAR can be calculated from induced electric field $(E)$ in the human tissues by using Eq. 3 [15]:

$S A R=\frac{\sigma|E|^{2}}{2 \rho}$,

where, $\sigma$ and $\rho$ express the electric conductivity and the mass density of human tissue respectively.

The unit of SAR is W/kg it is averaged over a specific mass of human body tissue. But, The TAP is measured in $\mathrm{W}$, which indicates the total absorbed power in the human body tissue from radiation.

Adopting the non-uniform meshing scheme, the majority of the computation was considered to regions along the inhomogeneous boundaries for quick and perfect investigation. In Lossy-Drude simulation setup [19], the domain was $128 \times 128 \times 128$ cells in the FDTD method. The cell sizes were set as $d x=d y=d z=3 \mathrm{~mm}$. The computational domain was terminated with 12 cells perfect material layer. The SAR evaluation for both antennas are performed in the post processing phase of the simulation using an identical SAR setting. A standard IEEE algorithm [20] is used to calculate the average SAR over $1 \mathrm{~g}$ of human head tissue using $1 \mathrm{~W}$ excitation for both antennas.

\section{RESULTS AND DISCUSSION}

In this paper, obtained results have been presented and discussed in two sub-headings comprising GSM $900 \mathrm{MHz}$ and DCS $1800 \mathrm{MHz}$ frequency band. For both frequencies of operation, comparison of PIFA and helical antenna has been performed considering SAR in the human head and TAP by the cell phone user. For each substrate material, two thicken sheet $0.8 \mathrm{~mm}$ and $1.6 \mathrm{~mm}$ are used to take effects of substrate thickness.

\subsection{SAR results at GSM frequency band}

The SAR values for helical antenna and PIFA with a variety of substrate materials and its thickness are plotted in Fig. 3 and Fig. 4 respectively at GSM frequency band. The results show that the substrate materials do not affect SAR values considerably for both PIFA and helical antenna. On the other hand, substrate thickness affects the SAR values significantly. The results indicate that, the higher substrate thickness produces comparatively lower SAR values for both antennas. The Bakelite substrate with $1.6 \mathrm{~mm}$ thickness reduces the SAR $2.26 \%$ for helical antenna and $14.88 \%$ for PIFA comparing with thickness $0.8 \mathrm{~mm}$ of same substrate. For the PIFA with $1.6 \mathrm{~mm}$ substrate, effects of materials on the SAR is noticeable. It is found that the Bakelite substrate leads to less SAR compared to other substrate materials and Taconic TLC leads to higher SAR for PIFA with a $1.6 \mathrm{~mm}$ substrate configuration. Moreover, Fig. 5 and Fig. 6 shows the TAP values for helical antenna and PIFA respectively.

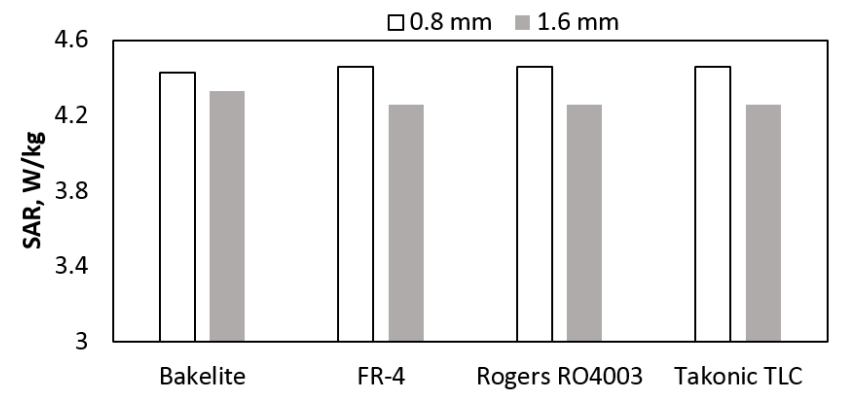

Fig. 3. SAR values for helical antenna with different substrates at $900 \mathrm{MHz}$

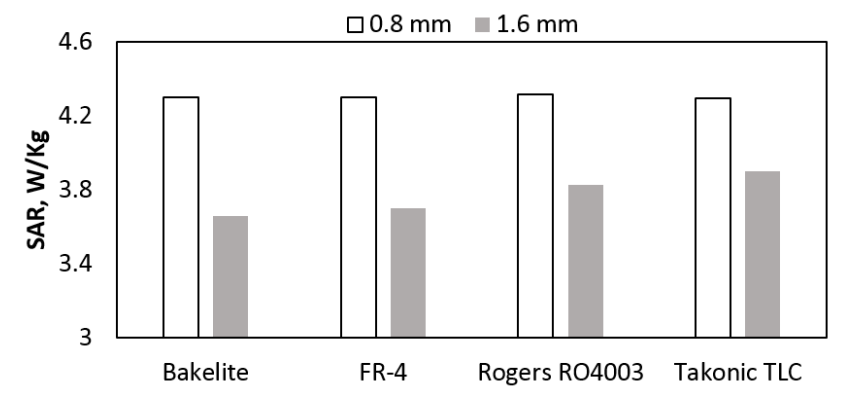

Fig. 4. SAR values for PIFA with different substrates at $900 \mathrm{MHz}$

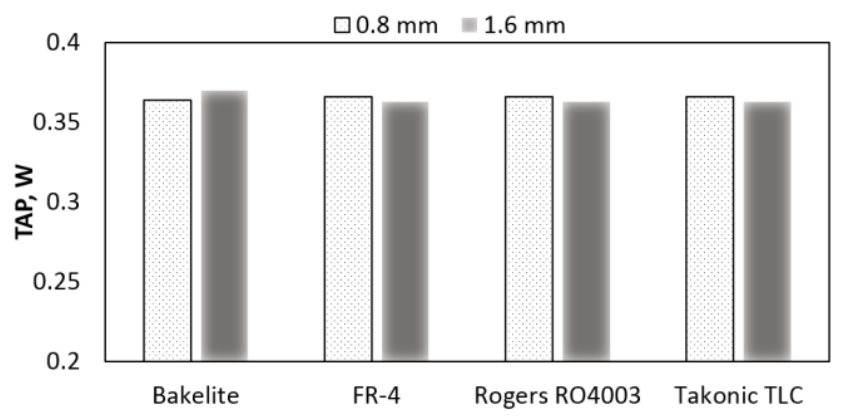

Fig. 5. TAP by used for helical antenna with different substrates at $900 \mathrm{MHz}$

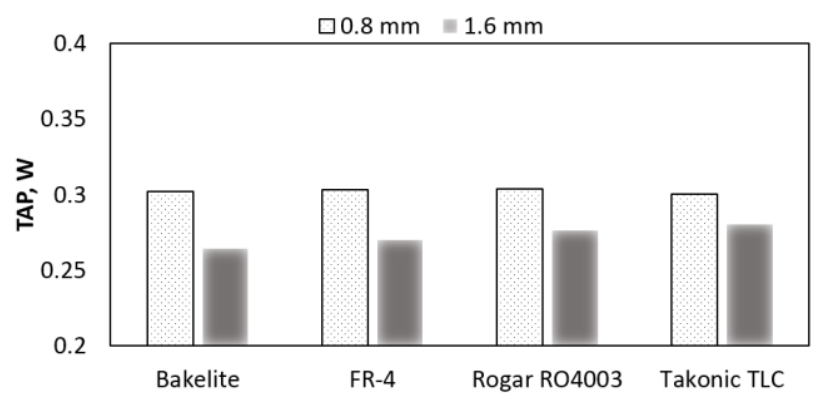

Fig. 6. TAP by cell phone user for PIFA with different substrates at $900 \mathrm{MHz}$

The TAP values for helical antenna are not affected for substrate materials and they exhibit little bit decrement for 
substrate thickness change from $0.8 \mathrm{~mm}$ to $1.6 \mathrm{~mm}$. The TAP values of a PIFA configuration show similar tendency as like as SAR values with the variation of substrate materials and its thickness. In case of a PIFA Substrate thickness change from $0.8 \mathrm{~mm}$ to $1.6 \mathrm{~mm}$, Bakelite substrate shows $12.6 \%$ and Taconic TLC shows $6.7 \%$ reduction in TAP.

\subsection{SAR results as DCS frequency band}

For DCS frequency band, the SAR values are plotted in Fig. 7 and Fig. 8 for helical antenna and PIFA respectively. At DCS frequency band, PIFA produces lower SAR values than helical antenna for all cases. It is also observed that the substrate material variation does not affect SAR values considerably for both antennas, but substrate thickness affects the SAR values significantly. At DCS frequency band, SAR values are increased after increasing substrate thickness, which is completely opposite tendency of SAR values at GSM frequency band. At $1800 \mathrm{MHz}, \quad 1.6 \mathrm{~mm}$ Bakelite substrate increases $10.40 \%$ SAR as compared with $0.8 \mathrm{~mm}$ substrates for helical antenna. Additionally, the SAR values of PIFA do not change for increasing substrate thickness significantly. Moreover, Fig. 9 and Fig. 10 indicate the TAP values for helical antenna and PIFA at $1800 \mathrm{MHz}$ respectively. The TAP results show lower values at the DCS frequency band for both antennas than that of GSM frequency band. Moreover, the variations of TAP values with substrate materials and its thickness are not significant at $1800 \mathrm{MHz}$ for both antennas.

The substrate of antenna does give impact on SAR values by varying different substrate materials and its thickness. Comparison has been made between this research and previous research of Husni et al [2] for intenal handset antenna (helical). The previous research [2] showed that the helical antenna with FR-4 substrate leads higher SAR than that of Rogers RO4003 at $900 \mathrm{MHz}$. This study also reports higher SAR is obtained for FR-4 substrate compared to Rogers RO4003, but the difference of those SAR values is very small. This is due to the fact that the Rogers RO4003 substrate was considered as a loss free material in [2]. In the present study, all substrate materials are considered as a lossy material. On the other hand, comparison has been made between this investigation and previous study of Hossain et al [21] for internal handest antenna (PIFA). This study also conferms the results presented in [21] that the increase in substrate thickness leads to reduce SAR in the human head in case of PIFA.

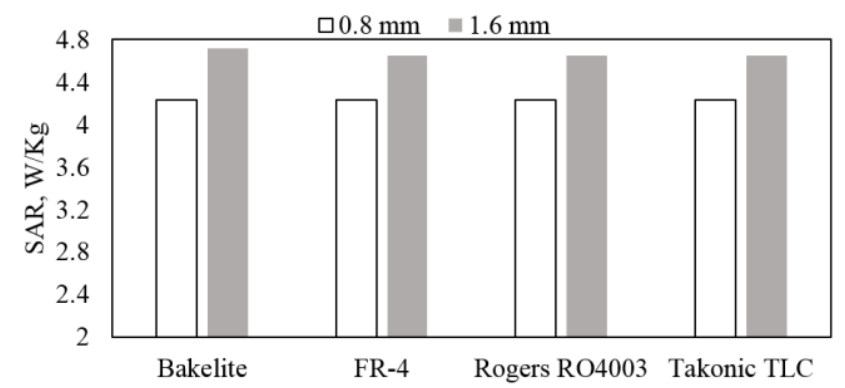

Fig. 7. SAR values for helical antenna with different substrates at $1800 \mathrm{MHz}$

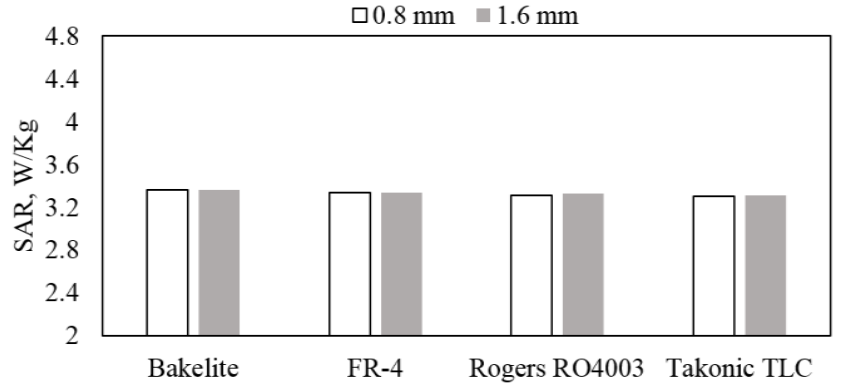

Fig. 8. SAR values for PIFA with different substrates at $1800 \mathrm{MHz}$

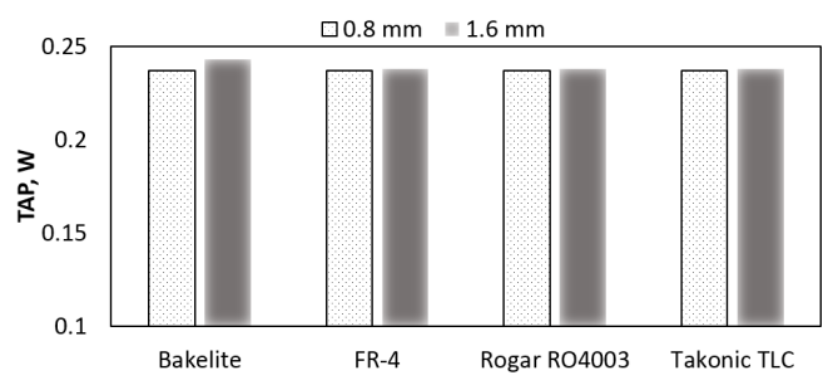

Fig. 9. TAP by cell phone user for a helical antenna at the DCS frequency band

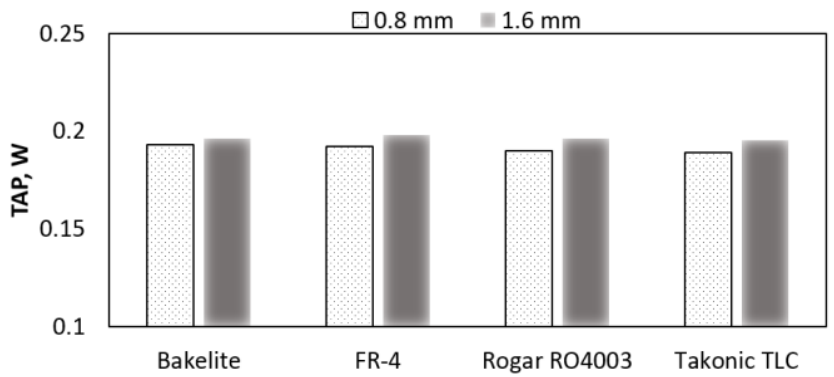

Fig. 10. TAP by user for PIFA at DCS frequency band

\section{CONCLUSION}

In this investigation, the effects of antenna substrate materials and its thickness on EM absorption have been analyzed with four different substrate materials. The helical antenna and PIFA are used to compare the substrate effects at frequencies $900 \mathrm{MHz}$ and $1800 \mathrm{MHz}$ considers SAR in the human head and TAP by the cell phone user. The results show that the substrate materials do not affect SAR values considerably for both PIFA and helical antenna at GSM and DCS frequency band. But, the substrate thickness affects the SAR values significantly in most of the cases. After increasing substrate thickness, SAR values are increased as a DCS frequency band and decreased at GSM frequency band. Moreover, PIFA produces lower SAR than that of a helical antenna significantly for both GSM and DCS frequency band. In addition, TAP values show similar variation as like as SAR values at $900 \mathrm{MHz}$ and exhibits little variations at 1800 $\mathrm{MHz}$ with different substrate materials and its thickness.

\section{REFERENCES}

1. Vrbova, B., Vrba, J. Microwave Thermotherapy in Cancer Treatment: Evaluation of Homogeneity of SAR Distribution 
Progress in Electromagnetics Research

2012: pp. $181-195$.

http://dx.doi.org/10.2528/PIER12032304

2. Husni, N. A., Islam, M. T., Faruque, M. R. I., Misran, N. Effects of Electromagnetic Absorption Towards Human Head Due to Variation of Its Dielectric Properties at 900, 1800 And 1900 Mhz with Different Antenna Substrates Progress in Electromagnetics Research 138 2013: pp. $367-388$.

3. Khurana, V. G., Teo, C., Kundi, M., Hardell, L., Carlberg, M. Cell Phones and Brain Tumors: A Review Including the Long-Term Epidemiologic Data Surgical neurology 72 (3) 2009: pp. 205-214.

http://dx.doi.org/10.1016/j.surneu.2009.01.019

4. Behari, J. Biological Responses of Mobile Phone Frequency Exposure Indian Journal of Express Biology 48 (10) 2010: pp. 959-981.

5. Hossain, M. I., $\quad$ Faruque, M. R. I., Islam, M. T., Hanafi, N. H. M. Application of Auxiliary Antenna Elements for SAR Reduction in The Human Head Advanced Materials Research 974 2014: pp. 288-292.

6. International Commission on Non-Ionizing Radiation Protection (ICNRIP). Health Issues Related to The Use of Hand-Held Radiotelephones and Base Transmitters Health Physics 70 1996: pp. 587-593.

7. Jerry, L., Ulcek, R. F., Cleveland, Jr. Evaluating Compliance with FCC Guidelines for Human Exposure to Radiofrequency Electromagnetic Fields Washington, DC: FCC Technical Report Supplement C to OET Bulletin 65 2001.

8. Faruque, M. R. I., Islam, M. T., Misran, N. SAR Analysis in Human Head Tissues for Different Types of Antennas World Applied Sciences Journal 11 (9) 2010: pp. 1089 - 1096.

9. Ebrahimi-Ganjeh, M. A., Attari, A. R. Interaction of Dual Band Helical and PIFA Handset Antennas with Human Head and Hand Progress in Electromagnetics Research 77 2007: pp. 225-242.

10. Stevens, N., Martens, L. Comparison of Averaging Procedures for SAR Distributions at 900 And $1800 \mathrm{MHz}$ IEEE Transactions on Microwave Theory and Techniques 48 (11) 2000: pp. 2180-2184. http://dx.doi.org/10.1109/22.884212

11. Alam, T., Faruque, M. R. I., Islam, M. T. Printed Circular Patch Wideband Antenna for Wireless Communication Informacije MIDEM 44 (3) 2014: pp. 212-217.

12. Pisa, S., Cavagnaro, M., Lopresto, V., Piuzzi, E., Lovisolo, G. A., Bernardi, P. A Procedure to Develop
Realistic Numerical Models of Cellular Phones for an Accurate Evaluation of SAR Distribution in The Human Head IEEE Transactions on Microwave Theory and Techniques 53 (4) 2005: pp. 1256-1265.

13. Beard Brian, B., Kainz, W., Onishi, T., Iyama, T., Watanabe, S., Fujiwara, O., Wang, J., et al. Comparisons of Computed Mobile Phone Induced SAR in The SAM Phantom to That in Anatomically Correct Models of the Human Head IEEE Transactions on Electromagnetic Compatibility 48 (2) 2006: pp. 397-407.

14. Laila, D., Sujith, R., Nair, S. M., Aanandan, C. K., Vasudevan, K., Mohanan, P. Mobile Antenna With Reduced Radiation Hazards Towards Human Head Progress In Electromagnetics Research Letters 17 2010: pp. 39-46.

15. Faruque, M. R. I., Aisyah-Husni, N., Hossain, M. I., Islam, M. T., Misran, N. Effects of Mobile Phone Radiation onto Human Head with Variation of Holding Cheek and Tilt Positions Journal of Applied Research and Technology 12 (5) 2014: pp. 871-876.

16. Lee, K. H., Ahmed, I., Goh, R. S. M., Khoo, E. H., Li, E. P., Hung, T. G. G. Implementation of The FDTD Method Based on Lorentz-Drude Dispersive Model on GPU For Plasmonics Applications Progress In Electromagnetics Research 116 2011: pp. 441-456. http://dx.doi.org/10.2528/PIER11042002

17. CST MICROWAVE STUDIO ${ }^{\circledR}$ High Frequency 3D Electromagnetic Field Simulation Software - Solvers available:https://www.cst.com/Products/CSTmws/FIT. [Accessed: 01-Nov-2014]; [Online].

18. Hwang, J.-N., Chen, F.-C. Reduction of The Peak SAR in The Human Head With Metamaterials Antennas and Propagation IEEE Transactions 54 (12) 2006: pp. $3763-3770$. http://dx.doi.org/10.1109/TAP.2006.886501

19. Pedersen, G. F., Andersen, J. B. Integrated Antennas for Hand-Held Telephones with Low Absorption IEEE Vehicular Technology Conference 1994: pp. 1537-1541.

20. IEEE. C95.3-2002 IEEE Recommended Practice for Measurements and Computations of Radio Frequency Electromagnetic Fields With Respect to Human Exposure to Such Fields, 100 kHz-300 GHzIEEE, New York, 2002.

21. Hossain, M. I., Faruque, M. R. I., Islam, M. T. Analysis of the Effects of Antenna Substrate Materials on SAR in the Human Head 22nd International Conference on Materials and Technology, Portoroz, Slovenia 2014: pp. 94-95. 